\title{
Decreased sperm survivability in subfertile Delaware roosters as indicated by comparative and competitive fertilization
}

\author{
J. D. Kirby, D. P. Froman, H. N. Engel, Jr* and P. E. Bernier \\ Department of Poultry Science, *College of Veterinary Medicine, Oregon State University, \\ Corvallis, Oregon 97331-3402, USA
}

\begin{abstract}
Summary. Duration of fertility following intravaginal and intramagnal insemination of hens with viable spermatozoa from subfertile Delaware roosters was compared with that obtained with spermatozoa from fertile Leghorns and subfertile Wyandotte roosters. In contrast to results with Leghorn and Wyandotte birds, duration of fertility was not increased following intramagnal insemination of spermatozoa from Delaware birds. Competitive fertilization also demonstrated that duration of fertility was less than expected in the spermatozoa from Delaware birds. Heritable subfertility in Wyandotte and Delaware roosters therefore appears to be attributable to distinct sperm defects.
\end{abstract}

Keywords: spermatozoa; chicken; fertility; sperm competition

\section{Introduction}

Froman \& Bernier (1987) identified a heritable reproductive disorder in roosters within a line of Delaware chickens maintained by the Oregon Agricultural Experiment Station. This disorder was characterized by sperm degeneration within the mid-and distal ductus deferens which appeared to account for the subfertility that originally drew attention to these roosters. Because seminal quality was improved by changing the frequency of ejaculation from a weekly to a daily basis, the extent of sperm degeneration appeared to depend upon the duration of sperm residence within the ductus deferens. Therefore, Froman \& Bernier (1987) suggested that a dysfunction of the ductus deferens resulted in sperm degeneration therein.

However, this hypothesis is tenable only if a sperm defect can be discounted. After spermiogenesis, chicken spermatozoa are maintained within the distal ductus deferens for several days before being ejaculated or voided into the cloaca (de Reviers, 1975). After ejaculation, chicken spermatozoa can be maintained within the hen's uterovaginal sperm storage glands for many days before being made available for fertilization (Bobr et al. 1964). Consequently, a diminished duration of fertility would be symptomatic of a sperm defect. Therefore, the objective of the present work was to assess the duration of fertility of viable spermatozoa ejaculated from roosters characterized by the reproductive disorder described by Froman \& Bernier (1987).

\section{Materials and Methods}

\section{Experiment 1}

Semen was collected from roosters representing 4 genotypes: Single Comb White Leghorn (SCWL; $N=3$ ), SilverLaced Wyandotte heterozygous for rose comb $(\mathrm{N}=4)$, subfertile Delaware $(\mathrm{N}=5)$, and Silver-Laced Wyandotte homozygous for rose comb $(\mathrm{N}=5)$. All roosters had been ejaculated weekly for $\geq 3$ weeks before this experiment. 
With the exception of the Delaware birds, roosters were ejaculated weekly throughout the experiment. Daily ejaculation of Delaware cocks began 4 days before the first insemination and continued every other day thereafter.

Semen was pooled according to rooster genotype. Percentages of viable spermatozoa as well as sperm concentrations were determined fluorometrically by ethidium bromide uptake (Bilgili \& Renden, 1984). Each of the 4 semen samples was diluted to $2.0 \times 10^{9}$ viable spermatozoa/ml with Beltsville Poultry Semen Extender, pH 7.5 (BPSE; a gift from Dr T Sexton, USDA, Beltsville, MD, USA). Each sperm suspension was used to intravaginally inseminate $30 \mathrm{SCWL}$ hens with $1 \times 10^{8}$ viable spermatozoa per hen. Three replicate fertility trials were completed for each rooster genotype.

Egg collection began on the 2nd day after insemination and continued for 21 days. Eggs were set weekly. Fertility was assessed by breaking eggs open after 4 days of incubation and examining the contents for embryonic development. Arc sine transformations of percentages of fertilized eggs were analysed by single classification analysis of variance (Sokal \& Rohlf, 1981)

Data were pooled when no difference $(P \geq 0.05)$ was observed among replicate fertility trials. Percentages of fertilized eggs were plotted by day. Because plots conformed to logistic functions, parameters of

$$
y(x)=\frac{\gamma}{1+\mathrm{e}^{\beta(1-x)}}
$$

were estimated by iterative least squares (Freund \& Littell, 1986a)

\section{Experiment 2}

Semen was collected and sperm suspensions prepared as above with two exceptions. First, semen from Wyandotte roosters heterozygous for rose comb was not used. Second, each sperm suspension contained $5 \times 10^{8}$ viable spermatozoa/ml. For each sperm suspension, each of 25-30 SCWL hens was inseminated intramagnally with $5 \times 10^{7}$ viable spermatozoa via laparotomy (Howarth, 1983). Egg collection, incubation, and data analyses were performed as above.

\section{Experiment 3}

Semen was collected from the Delaware roosters used in the preceding experiments as well as from 5 Brown Leghorns. The latter had been characterized as having a fertilizing ability equivalent to that of the SCWL roosters $(P>0.05)$. Ejaculates were pooled according to breed. After the seminal evaluations described above, the semen samples from the Delaware and Brown Leghorn birds were diluted with BPSE to $2.0 \times 10^{9}$ viable spermatozoa $/ \mathrm{ml}$. Equal volumes of these sperm suspensions were mixed, and each of 40 New Hampshire hens was inseminated intravaginally with $1 \times 10^{8}$ viable spermatozoa from this mixture.

Eggs were collected and set as above. However, eggs were incubated for 21 days and down colour of chicks was assessed at hatch. Down colour was also recorded for feathered chicks that failed to hatch. Percentages of chicks sired by Delaware birds were plotted by day. Parameters of

$$
y(x)=\alpha+\beta_{1} x+\beta_{2} x^{2}
$$

were estimated by weighted least squares (Freund \& Littell, 1986b).

\section{Experiment 4}

Semen was collected and sperm suspensions prepared according to the preceding experiment with one exception: each sperm suspension conained $5 \times 10^{8}$ viable spermatozoa $/ \mathrm{ml}$. Each of the 40 New Hampshire hens used in the preceding experiment was inseminated intramagnally (Howarth, 1983) with $5 \times 10^{7}$ viable spermatozoa. Egg collection, incubation, and chick down colour were determined as above. Parameters of

$$
y(x)=\alpha+\beta x
$$

were estimated by least squares (Freund \& Littell, 1986a).

\section{Results}

As shown in Table 1, daily ejaculation of subfertile Delaware roosters for 5 consecutive days and every other day thereafter yielded percentages of viable spermatozoa that were comparable to those of Leghorn and Wyandotte birds. However, as shown in Table 2, sperm fertilizing ability was not equivalent among rooster genotypes. The means in Table 2 represent those of pooled data as no differences were observed $(P>0.05)$ among replicate fertility trials. The fertilizing ability of spermatozoa from Delaware birds was intermediate $(P<0.001)$ between that of Wyandottes homozygous for rose comb, which are known to be characterized by subfertility (Crawford \& Merritt, 1963), and that of Wyandottes heterozygous for rose comb, which like Leghorns, are not subfertile. 
Table 1. Percentages of viable spermatozoa ejaculated by 4 genotypes of rooster

\begin{tabular}{lccc}
\hline $\begin{array}{c}\text { Breed of } \\
\text { rooster }\end{array}$ & $\begin{array}{c}\text { No. of } \\
\text { birds }\end{array}$ & $\begin{array}{c}\text { Comb } \\
\text { genotype }\end{array}$ & $\begin{array}{c}\text { Sperm } \\
\text { viability } \\
(\%)\end{array}$ \\
\hline White Leghorn & 3 & rrpp & $100 \pm 0.0$ \\
Wyandotte & 4 & Rrpp & $100 \pm 0.0$ \\
Delaware & 5 & rrpp & $98 \pm 1 \cdot 1$ \\
Wyandotte & 5 & RRpp & $96 \pm 1 \cdot 0$ \\
\hline
\end{tabular}

Values represent the mean \pm s.e.m. for 3 replicates of pooled semen.

Table 2. Fertility of Single Comb White Leghorn hens over a 21-day egg collection interval following a single intravaginal or intramagnal insemination with $1 \times 10^{8}$ and $5 \times 10^{7}$ viable spermatozoa, respectively

\begin{tabular}{llccc}
\hline $\begin{array}{l}\text { Insemination } \\
\text { route }\end{array}$ & $\begin{array}{c}\text { Breed of } \\
\text { semen donors }\end{array}$ & $\begin{array}{c}\text { Comb } \\
\text { genotype }\end{array}$ & $\begin{array}{c}\text { No. of } \\
\text { eggs }\end{array}$ & $\begin{array}{c}\text { Fertility } \\
(\%)\end{array}$ \\
\hline Intravaginal & White Leghorn & rrpp & 1366 & $51 \pm 1 \cdot 2^{*}$ \\
& Wyandotte & Rrpp & 1360 & $47 \pm 1 \cdot 4^{*}$ \\
& Delaware & rrpp & 1295 & $42 \pm 1 \cdot 3$ \\
& Wyandotte & RRpp & 1348 & $26 \pm 1 \cdot 4^{*}$ \\
Intramagnal & White Leghorn & rrpp & 161 & $64 \pm 1 \cdot 2^{*}$ \\
& Delaware & rrpp & 202 & $41 \pm 0.4$ \\
& Wyandotte & RRppp & 176 & $57 \pm 1 \cdot 0^{*}$ \\
\hline
\end{tabular}

Fertility values are mean \pm s.e.m.

${ }^{*} P<0.001$ compared with that for Delaware roosters.

Fertility after intramagnal insemination of spermatozoa from Leghorn, Delaware or subfertile Wyandotte roosters is shown in Table 2 . When compared to values obtained with intravaginal insemination, fertility for the Leghorn and subfertile Wyandotte birds increased by 13 and $30 \%$, respectively, but there was no change for Delaware roosters.

These relationships were more evident after graphical analyses (Fig. 1). Estimates of $\tau$, time at which half-maximal fertility occurred, were $11 \cdot 8,9 \cdot 1$ and 6.0 days after intravaginal insemination for Leghorn, Delaware and subfertile Wyandotte birds, respectively, and 15.2, 9.6 and 13.9 days after intramagnal insemination. For spermatozoa from Delaware cocks, the hypothesis that $9 \cdot 1$ and 9.6 were estimates of the same unknown parameter was not rejected $(P>0.05)$. Thus, unlike the spermatozoa from the Leghorn and subfertile Wyandotte birds, intramagnal insemination of those from Delaware birds failed to increase duration of fertility.

When New Hampshire hens were inseminated intravaginally or intramagnally with spermatozoa from Delaware and Brown Leghorn roosters, most chicks were sired by Brown Leghorns (Table 3). As shown by the fitted curves in Fig. 2, percentages of chicks sired by Delaware birds were not constant throughout egg collection intervals. The hatch of fertile eggs after intramagnal insemination (Table 3) also shows that the insemination dose of $5 \times 10^{7}$ spermatozoa did not increase the incidence of embryonic mortality.

\section{Discussion}

Heritable subfertility in roosters has been reported in two instances: roosters homozygous for rose comb (RR; Crawford \& Merritt, 1963) and Delaware roosters (Froman \& Bernier, 1987). The 


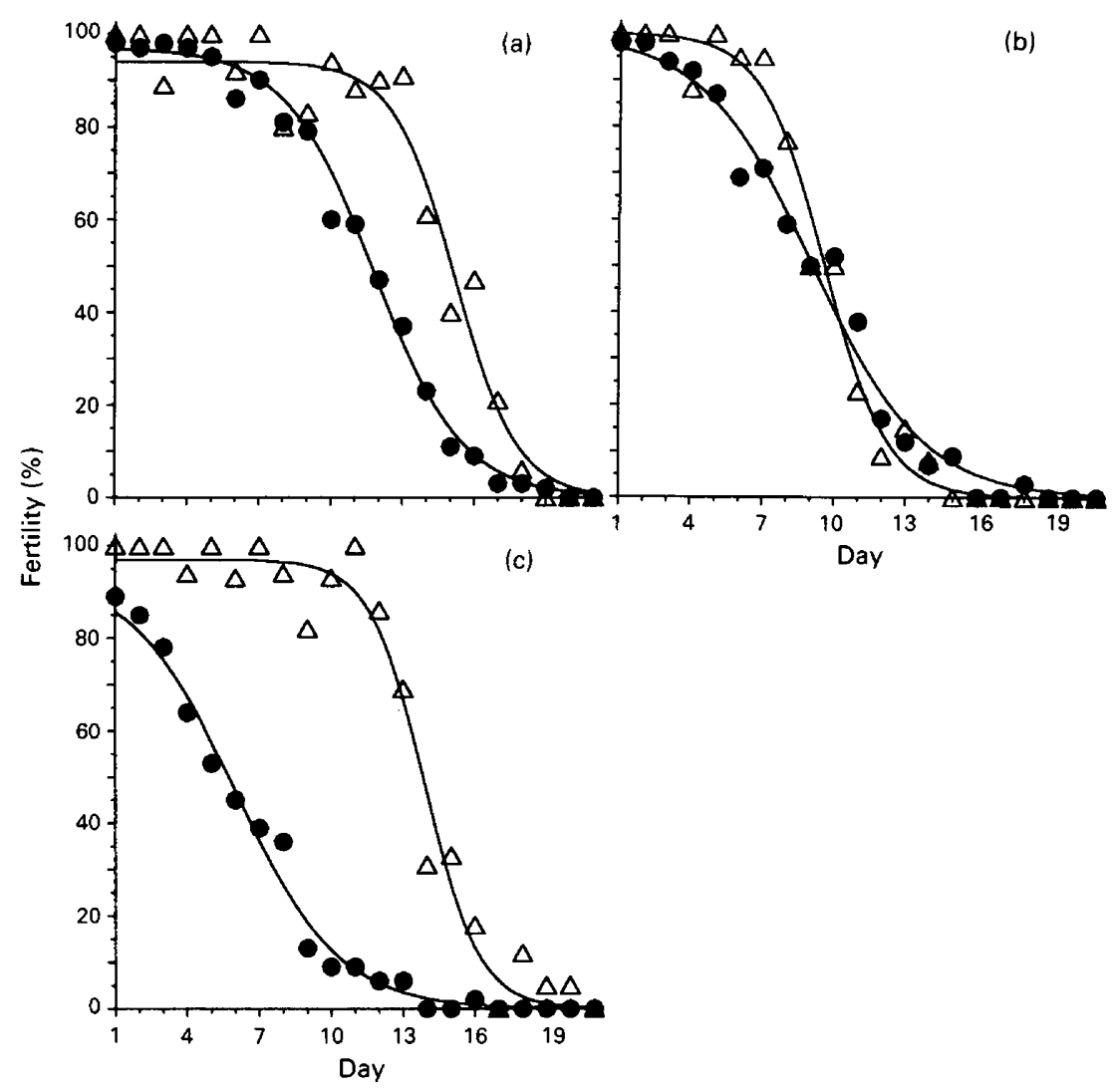

Fig. 1. Duration of fertility after intravaginal $(\bullet)$ and intramagnal $(\triangle)$ insemination of Single Comb White Leghorn hens with spermatozoa from (a) Single Comb White Leghorn roosters, (b) Delaware roosters, and (c) Wyandotte roosters homozygous for rose comb. Insemination doses were $1 \times 10^{8}$ and $5 \times 10^{7}$ viable spermatozoa, respectively. Solid lines represent the functions

$$
\begin{aligned}
& \text { (a) } y(x)=\frac{97}{1+\mathrm{e}^{-0.5340(11 \cdot 8-x)}} \text { and } y(x)=\frac{94}{1+\mathrm{e}^{-0.7634(15 \cdot 2-x)}} \text {, } \\
& \text { (b) } y(x)=\frac{100}{1+\mathrm{e}^{-0.4266(9 \cdot 1-x)}} \text { and } y(x)=\frac{100}{1+\mathrm{e}^{-0.7507(9 \cdot 6-x)}} \text {, } \\
& \text { and (c) } y(x)=\frac{94}{1+\mathrm{e}^{-0 \cdot 4653(6 \cdot 0-x)}} \text { and } y(x)=\frac{97}{1+\mathrm{e}^{-0.8782(13 \cdot 9-x)}} \text {. }
\end{aligned}
$$

latter are characterized by a single comb and a Columbian feather colour pattern. In each case, subfertility has been attributed to reduced sperm fertilizing ability. However, the mechanisms responsible for subfertility appear to be distinct.

Buckland et al. (1969) attributed subfertility in RR roosters to a reduced sperm fumarase activity and suggested that this difference might affect sperm survivability within the oviduct. In view of the duration of fertility observed following the intramagnal insemination of RR Wyandotte spermatozoa (Fig. 1c) as well as the inability of Petitjean \& Servouse (1981) to detect reduced fumarase activity in extracts of spermatozoa from RR roosters, the hypothesis of Buckland $e t$ al. (1969) is untenable. Petitjean \& Servouse (1981) did, however, report that spermatozoa from RR roosters were characterized by poor motility. Thus, in agreement with Etches et al. (1974), 
Table 3. Comparison of fertility, hatchability, and paternity of chicks from eggs laid by New Hampshire hens over a 2-week interval following insemination with spermatozoa from Delaware and Brown Leghorn roosters

\begin{tabular}{lcccc}
\hline $\begin{array}{c}\text { Type of } \\
\text { insemination }\end{array}$ & $\begin{array}{c}\text { No. of } \\
\text { eggs }\end{array}$ & $\begin{array}{c}\text { Fertility } \\
(\%)\end{array}$ & $\begin{array}{c}\text { Hatch of } \\
\text { fertilized } \\
\text { eggs }(\%)\end{array}$ & $\begin{array}{c}\text { Chicks } \\
\text { sired by } \\
\text { Delawares } \\
(\%)\end{array}$ \\
\hline Intravaginal & 407 & 69 & 71 & 36 \\
Intramagnal & 365 & 70 & 75 & 33 \\
\hline
\end{tabular}

Insemination doses were $1 \times 10^{8}$ and $5 \times 10^{7}$ viable spermatozoa per hen for intravaginal and intramagnal inseminations, respectively. In either case, $50 \%$ of the spermatozoa inseminated were from Delaware roosters.

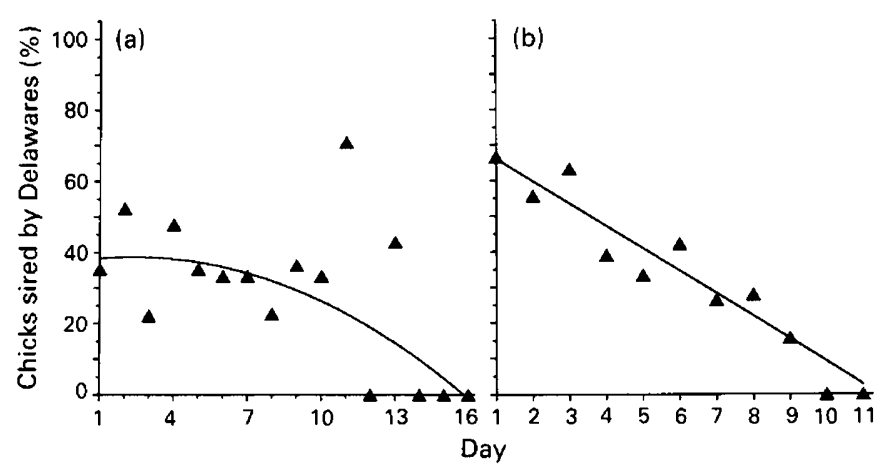

Fig. 2. Percentages of chicks sired be Delaware roosters ( $\boldsymbol{\Delta}$ ) following (a) intravaginal and (b) intramagnal insemination of New Hampshire hens with equal numbers of spermatozoa from Delaware and Brown Leghorn roosters. In (a) the solid line $\left(R^{2}=0 \cdot 87\right)$ represents the function

$$
y(x)=37 \cdot 5+1 \cdot 01(x)-0 \cdot 214\left(x^{2}\right),
$$

and the datum from Day 11 was excluded from the estimation of the fitted curve as a consequence of outlier detection (Freund \& Littell, 1986c). In (b) the solid line $\left(R^{2}=0.94\right)$ represents the function

$$
y(x)=68.9-5 \cdot 6(x)
$$

the subfertility of RR Wyandotte birds after intravaginal insemination (Fig. 1c) may be attributable to inadequate sequestration of spermatozoa within the uterovaginal sperm storage glands.

In contrast, Froman \& Bernier (1987) concluded that sperm degeneration accounted for subfertility of Delaware roosters. Theoretically, sperm degeneration within the ductus deferens could be the consequence of an autoimmune condition, a dysfunction of the ductus deferens, or a sperm defect. The autoimmunity hypothesis has been tested and rejected (unpublished data). Of the two remaining hypotheses, sperm autolysis warranted investigation first because such a phenomenon, were it to occur, would confound any investigation of the sperm maintenance function of the ductus deferens. We proposed that, if an aberrant duration of fertility were 
observed following the insemination of viable Delaware spermatozoa, then a sperm defect would be likely.

In Exp. 1, the fertilizing ability of spermatozoa from Delaware roosters was compared with those of a genotype characterized by subfertility and two genotypes that are not. As shown in Table 2 , the fertilizing ability of Delaware birds was intermediate $(P<0.001)$ between that of the RR and $\operatorname{Rr}$ Wyandottes. Even so, the fertilizing ability of Delaware chicken spermatozoa after intravaginal insemination was more comparable to that of the Rr Wyandotte as well as New Hampshire and Barred Plymouth Rock birds (unpublished data) than it was to that of RR Wyandotte roosters. The implicit ranking of fertilizing abilities in Table 2 is not only typical among breeds but also among individuals within breeds (Allen \& Champion, 1955; Martin \& Dziuk, 1977). The fertilizing ability of spermatozoa from Delaware roosters in Exp. 1 was more typical of spermatozoa from American breeds than that of subfertile roosters per se.

However, when intramagnal inseminations were performed, spermatozoa from Delaware birds failed to yield fertility greater than that observed following intravaginal insemination. As was expected based upon the work of Van Krey et al. (1966), intramagnal insemination with spermatozoa of SCWL birds increased fertility (Fig. 1a). This was also true with spermatozoa from RR Wyandottes (Fig. Ic). The latter observation may be explicable in terms of circumventing sperm sequestration within the uterovaginal sperm storage glands; Howarth (1983) demonstrated that intramagnal insemination of testicular spermatozoa, which are characterized by poor motility and an inability to fertilize ova following intravaginal insemination, yielded fertility equivalent to that obtained with ejaculated spermatozoa similarly inseminated. Because the two estimates of $\tau$ appeared to be independent estimates of the same unknown parameter only in the case of Delaware spermatozoa, we concluded that intramagnal insemination of spermatozoa from Delaware birds revealed an aberrant duration of fertility.

Competitive fertilization was performed to characterize further the fertilizing ability of viable spermatozoa from affected Delaware roosters. According to Martin et al. (1974), the insemination of hens with equal numbers of spermatozoa from Leghorns and Columbian roosters yielded disproportionate numbers of offspring, but the proportions were constant over a 15-day egg collection interval. We anticipated a declining proportion of chicks sired by Delaware roosters under similar conditions. In these experiments, Brown Leghorns were used rather than White Leghorns because the former sire a brown chick when crossed with a New Hampshire hen whereas Delawares and White Leghorns sire yellow chicks. Preliminary work had shown that the fertilizing ability of spermatozoa of Brown Leghorns was equivalent to that of spermatozoa from White Leghorns $(P>0.05)$. More importantly, preliminary work had also shown that there was no difference in the percentage of embryonic dead when New Hampshire hens were inseminated with spermatozoa from Brown Leghorn or Delaware cocks $(P>0.05)$. As expected, the proportion of chicks sired by Delaware roosters declined as a function of time following intravaginal and intramagnal insemination (Fig. 2). However, the high percentage of chicks sired by Delaware roosters over the first 3 days after intramagnal insemination was not anticipated.

Froman \& Bernier (1987) observed that once the percentage of degenerate spermatozoa in ejaculates from subfertile Delaware roosters had been reduced to $\leqslant 5 \%$ via frequent ejaculation, the amount of sperm degeneration increased after 3 and was maximal after 12 days of sexual rest. In the present work, daily fertility following the intramagnal insemination of spermatozoa from Delaware birds decreased from 100 to $14 \%$ over a 12-day interval. In contrast, when equal numbers of spermatozoa from SCWL and RR Wyandotte birds were inseminated similarly, daily fertility was $\geq 80 \%$ over the same interval. It therefore appears that heritable sperm degeneration within the ductus deferens of the chicken may be attributable to a sperm defect. A premature activation of sperm metabolism might account for sperm degeneration within the ductus deferens and the transient initial superiority of spermatozoa from Delaware roosters.

Paper No. 8697 of Oregon Agricultural Experiment Station. 


\section{References}

Allen, C.J. \& Champion, L.R. (1955) Competitive fertilization in the fowl. Poultry Sci. 34, 1332-1342.

Bilgili, S.F. \& Renden, J.A. (1984) Fluorometric determination of avian sperm viability and concentration. Poultry Sci. 63, 2275-2277.

Bobr, L.W., Lorenz, F.W. \& Ogasawara, F.X. (1964) Distribution of spermatozoa in the oviduct and fertility in domestic birds. I. Residence sites of spermatozoa in fowl oviducts. J. Reprod. Fert. 8, 39-47.

Buckland, R.B., Wilcox, F.H. \& Shaffner, C.S. (1969) Influence of homozygosity for rose comb on fumarase, aconitase, isocitric dehydrogenase and malic dehydrogenase activity in spermatozoa of the domestic fowl (Gallus domesticus). J. Reprod. Fert. 18, 89-95.

Crawford, R.D., \& Merritt, E.S. (1963) The relation between rose comb and reproduction in the domestic fowl. Can. J. Genet. Cytol. 5, 89-95.

de Reviers, M. (1975) Sperm transport and survival in male birds. In The Biology of Spermatozoa, pp. 10-16. E. S. E. Hafez and C. B. Thibault. Karger, Basel.

Etches, R.J., Buckland, R.B. \& Hawes, R.O. (1974) The effect of the genes for rose comb and polydactyly on sperm transport in the hen's oviduct. Poultry Sci. 53, $422-424$.

Freund, R.J. \& Littell, R.C. (1986a) Observations. In SAS System for Regression, pp. 47-74. SAS Institute Inc., Cary, NC.

Freund, R.J. \& Littell, R.C. (1986b) Polynomial models. In SAS System for Regression, pp. 103-126. SAS Institute Inc., Cary, NC.
Freund, R.J. \& Littell, R.C. (1986c) Using PROC REG. In SAS System for Regression, pp. 15-46. SAS Institute Inc., Cary, NC.

Froman, D.P. \& Bernier, P.E. (1987) Identification of heritable spermatozoal degeneration within the ductus deferens of the chicken (Gallus domesticus). Biol. Reprod. 37, 969-977.

Howarth, B., Jr (1983) Fertilizing ability of cock spermatozoa from the testis, epididymis, and vas deferens following intramagnal insemination. Biol. Reprod. 28, 586-590.

Martin, P.A. \& Dziuk, P.J. (1977) Assessment of relative fertility of males (cockerels and boars) by competitive mating. J. Reprod. Fert. 49, 323-329.

Martin, P.A., Reimers, T.J., Lodge, J.R. \& Dziuk, P.J. (1974) The effect of ratios and numbers of spermatozoa mixed from two males on proportions of offspring. J. Reprod. Fert. 39, 251-258.

Petitjean, M. \& Servouse, M. (1981) Comparative study of some characteristics of the semen of RR (rose comb) or rr (single comb) cockerels. Reprod. Nutr. Develop. 6B, 1085-1093.

Sokal, R.R. \& Rohlf, F.J. (1981) Single classification analysis of variance. In Biometry, 2nd edn, pp. 20-270. Freeman, New York.

Van Krey, H.P., Ogasawara, F.X. \& Lorenz, F.W. (1966) Distribution of spermatozoa in the oviduct and fertility in domestic birds. IV. Fertility of spermatozoa from infundibular and uterovaginal glands. J. Reprod. Fert. 11, 257-262. 